millimeters with a charge of 108 kilogrammes of guncotton, the explosive force of which is four times that of gun-powder. The weight of the projectile is 2,600 pounds; the range, 9,000 meters, the early velocity 42 knots, which is maintained up to 2,000 meters, with the final velocity not less than 28 knots. The price of such a projectile is about $\$ 4,000$. The new French armored ships are furnished with six torpedo tubes below the water-line and protected against

while the submarines now carry eight tubes.
England uses torpedoes of 533 millimeters caliber England uses torpedoes of 533 millimeters caliber
of the Armstrong \& Hardcastle models, with an early of the Armstrong \& Hardcastle models, with an early
speed of 45 knots and ability to maintain high speed, and the charge is 130 kilogrammes of explosive.

Germany places on board its armored ships a torpedo of 530 millimeters with 128 kilogrammes of explosive, while the cruisers and torpedo boats use another model of 500 millimeters, but with the shorter range of 4,000 meters. Studies have been made with torpedoes of 600 millimeters with great speed and range.

Russia is the only power besides France that has kept to the model of 450 millimeters, but with a heavier charge, 125 kilogrammes. The range of the Whiteheads uses is greater than 6,000 meters.

In the United States the model adopted is the BlissLeavitt (see illustration) of 533 millimeters diamete with 128 kilogrammes charge, capable of making 36 knots at 1,000 meters and 30 knots at 4,000 meters. Experiments have been made with others of the projectiles with effective distances up to 9,500 meters.

As to modern tactics with these terrible weapons, it consists no longer of isolated shots, but in volley fires. Such a discharge of a number of torpedoes against a line of ships is considered as sure of results. The torpedo boats under such circumstances will have some advantages, for after the first phases of a naval comba a certain amount of confusion is likely to be produced by some of the vessels showing signs of weakness, and then they can charge the fleet in a body. This may take them to within 2,000 or 3,000 meters of the enemy, and without doubt they can from there send out torpedoes that will be pretty certain to hit. It is generally estimated that at 4,000 meters 30
per cent of the torpedoes will be effective. If this were only ten per cent, and out of 40 projectiles 4 explode and put out of the battle two or three vessels, the attacking fleet will have achieved enormous results. Torpedoes have the general form of a cigar, being about 5 to 6 meters in length with a diameter of about 450 millimeters. The body is of steel, and consists of four sections firmly screwed together. The head, about one eighth of the whole length, is conical in form, and within it is the explosive furnished with the percussion apparatus, which, when the projectile strikes an obstacle, ignites the priming and causes the explosion. Behind this is the second section with the air reservoir, a steel cylinder containing compressed air for the motors and machinery. The third section may be called the engine room, where there are the various devices for propulsion, steering-both laterally and verticallyetc., and behind this a combination of shaft-room and rudder runs. There are two propeller shafts, one within the other, each with its own screw. The propellors are in a kind of case of square frames, the pattern of which varies in the different torpedoes, which furnish bearings for the propellers and supports for the rudders.

\title{
The Atlas of Finland"
}

\section{A Model Geographical Work of a Little Known but Interesting Country}

\section{Review by Gustave Regelsperger}

[T'he beautiful work, of which the French edition bear the title "Atlas de Finlande, 1910," was published at Helsingfors, in 1911, by the Society of Geography of Finland. It is a statistical atlas of very wide scope, its nearest American parallel being the "Statistical Atlas of the United States," which our Bureau of the Census issues periodically, and of which a new edition will probably appear during the present autumn. There are, however, important differences between these two works, as to scope and treatment. The Finnish atlas, with its two accompanying volumes of text, is, in fact, unique as a complete compendium of the geography of a country; using the term "geography" in it broadest sense. In scholarship and workmanship it is hardly surpassed in the whole range of geographical literature.-EDitor.]

LyiNg between Sweden and Russia, Finland pertain geographically and geologically to the former. In the north it is in no way distinguished from Sweden, whose dense forests are continued across the border. In the south it consists of a lacustrine plateau, resembling that of Smäland, which, on the other side of the Baltic, form the southern extremity of Sweden; both are covered by a complicated network of lakes and interconnecting water-courses. In spite of its affinities with Sweden however, Finland well deserves to be studied as a separate geographical unit, in view of its pronounced topographic features, its position between Sweden and Russia, and its outline, in virtue of which it forms a large peninsula between the Gulf of Bothnia on the one hand and the Gulf of Finland, prolonged by Lake Ladoga, on the other. Finland may, in fact, be considered as forming in certain respects a transition between the two countries which border it. It lacks the high mountains of Sweden, its relief not surpassing that of the eastern coast of the Scandinavian peninsula, so that we may regard it as a step leading from the high terraces of Sweden to the marshes of the Baltic provinces of Russia and the plain stretching thence to the Ural and the Caucasus.

However, the individuality of Finland as a country is due in even larger measure to its population; the Finns, who are greatly in the majority, being a totally different race from those which inhabit the neighboring countries On account of their position, the Finns have necessarily been subject to attacks and invasions on the part of the Swedes and the Russians, and the history of Finland is made up chiefly of these struggles. Though generally preserving more or less autonomy, Finland has never been entirely independent. For centuries it was ruled by Sweden, and it is now a part of Russia. Yet, as the home of the Finnish people, with only a small Swedish element, and a still smaller Russian, it has withstood the efforts of Russia to assimilate it to herself, and preserves unmistakably the germs of an independent national existence. Impelled on the one hand by the patriotic idea of making the Finnish people better acquainted with their country and with themselves, and on the other hand by an ambition to contribute to the general fund of geographical knowledge, the Society of Geography of Finland determined to present a detailed record of both the physical and the human geography of this interesting land, and in the fulfillment of this produced a work of the highest rank.

The first edition of the atlas appeared in 1899 , and was the development of material presented by the society at the Sixth International Geographical Congress, held in * Abstracted from Revue Généraie des Sciences.
London in 1895. The edition now under review bears imprint 1911. The committee responsible for its production had at its head Colonel and ex-Governor Max Alfthan, who was a member of the committee which compiled the earlier edition, and three other members of the same committee, viz., J. A. Palmén, secretary of the society; Prof. J. J. Sederholm, director of the Geological Commission; and E. G. Palmén, professor of Scandi-
navian and Finnish history at the University of Ilelsingnavian and Finnish history at the University of Ilelsing
fors; also two new members, viz., Mr. Onni Olila, chie of the Cartogurent and Dr. K. R. von Willebrand, chief engineer in the Department of Roads and Bridges. As compared with the 32 sheets of the first edition, the second contains 55 while the text, which also contains numerous charts, illustrations, and graphs, has more than tripled. The atlas volume is issued in a single edition, with titles and explanations in Finnish, Swedish and French; while of the two text volumes there is a separate edition for each of these three languages. The French translation is by Prof. J. Poirot, of Ielsingfors. The atlas is divided into two parts, to each of which corresponds one of the volumes of text; the first devoted to the physical geography of the country, the second to its human aspects.

$$
\text { I. PHYSICAL GEOGRAPHY }
$$

In his exposition of Chart I-the general map of Finland-Mr.Olila traces the history of Finnish cartography. The earliest charts date from the fifteenth and sixteenth centuries. That of Olaus Magnus (1539) is noted as having been the first to give a tolerably correct idea of the configuration of the country as a whole, and its position with respect to the adjoining countries. The earliest productions of serious merit, however, appeared in the fore-part of the seventeenth century, and were issued under the auspices of Charles IX., of Sweden. One by Andreas Bureus (1626), reproduced in the present atlas, was a remarkable work for its time, though it shows a non-existent chain of mountains running through the middle of the country. In the eighteenth century new surveys were made, in connection with the division of lands and the fixing of taxes, and these led to the excellent series of charts published from 1797 to 1807 under the auspices of Baron IIermelin. Parish charts on a uniform scale ( 1 to 20,000$)$ were issued by the government survey department between 1840 and 185G, as well as charts of districts, based upon these, on a scale of 1 to 100,000 . A general map of Finland in 30 sheets, based on a network of points fixed astronomically, was issued by the government in 1863-72. Only two exten sive geodetic surveys were, however, made in Finland during the nineteenth century; viz., that of the RussoScandinavian meridian, extending from the mouth of the Danube to the Arctic Ocean, executed from 1816 to 1855 , which crossed Finland; and the Baltic triangulation made
from 1828 to 1838 by the Russian authorities, under the from 1828 to 1838 by the Russ

The general chart published in the atlas on a scale of 1 to $2,000,000$ was drawn up by the society itself, with the use of all available material, and is based upon about 500 accurately determined positions. The same chart, with or without reduction, is used as a base-map for the other charts of the atlas.

Chart I shows the political subdivisions and the hydrography, but not the relief. Chart II is hypsometric. From this chart it is evident that no part of Finland is truly mountainous except the extreme northwest corner, which projects deep into the Scandinavian peninsula, to which geographically it belongs. In fact, the culminating point of Finland, Halditschokko, which attains only 4,440 western on the frontier. Aside from this small northtainous country. Seen from a balloon it would appear remarkably flat, but it really comprises innumerable small irregularities. Over the greater part of its surface the altitude varies between 300 and 1,300 feet above sealevel.

Throughout Finland there is an extraordinary abundance of water. Including the Finnish portion of Lake Ladoga, 11.73 per cent of the entire surface of the country is made up of lakes and streams. In the south, especially, the lakes are innumerable, while bogs and marshes are found everywhere. Southern Finland, which presents the most characteristic landscapes of the country, has been called "the land of a thousand lakes"-but "tens of thousands" would be a more accurate deseription. Chart 12 of the atlas, showing this lacustrine plateau, presents a truly fantastic appearance. This chart alone includes 9,600 lakes; while a chart of all Finland, on a scale of 1 to 400,000, includes no less than 35,500. The surface of the country may be compared to a sponge full of water which has been stretched out from southeast to northwest, as nearly all the water-courses and the majority of the lakes trend in that direction.

The shores of these lakes are extremely cut up with bays and inlets, and their bottoms are extremely uneven, and rarely of much depth. Chains of lakes are very common. The streams which drain the various lake basins are interspersed with rapids, generally of moderate gradient. Chart 14 shows the location of these rapids, and the water-power which each is capable of furnishing at low stage.

The peculiar hydrography of Finland is explained by its geological history. The atlas treats the geology of the country historically. Chart 3 shows the prequaternary rocks, and Chart 4 the quaternary deposits; whil several additional charts, on a smaller scale, deal with the history of the whole Fenno-Scandinavian region, showing the progress and effects of quaternary glaciation and the fracture lines due to violent earthquakes in the tertiary period.

The soil of Finland consists chiefly of hard crystalline rocks-granites, gneiss and schistes-formed at a very early period. A coarse red granite known as rapakivi i characteristic of the country. The commonest sediment ary rocks of this region are pre-Cambrian. These earlie formations show marked folding, the folds running from southeast to northwest, and this direction was subsequently followed by the glaciers. IIence the curious appearance of the lacustrine plateau, which looks as if an immense harrow had been drawn across it. Before the glacial period, however, the country had been fissured in all directions by violent upheavals and subsidences. The wonderfuf modern network of lakes is, therefore, due to the same combination of causes which produced the similar lacustrine landscapes of Sweden, Russian Karelia and Canada.

The same process which produced the Finnish lakes gave rise to the remarkable Aland and Abo archipelago, lying off the southwest extremity of the country. Thi consists of numerous large islands and a myriad of islets, rocks and shoals, spread like grains of dust over the chart (No. 10). It is aptly described by Prof. Selerholm as a 
submerged landscape of lakes, i. e., the same landscape that prevails over southern Finland extended out into the sea.

An important series of charts deals with the hydrography of the adjacent seas, viz., the Gulf of Bothnia and the Gulf of Finland, showing the limits of ice, temperatures at various depths and at various seasons; maximum and minimum temperature at the bottom, salinity, oxygen content, surface currents, tides, color and transparence. There are also bathymetric charts of the (Gult of Finland and Lake Ladoga, showing both these bodies of water to be relatively shallow.

Four plates of the atlas (Nos. 16-19) consist of meteorological charts. The accompanying text, by Dr. O. V. Johannson, of the Central Meteorological Institute, in cludes a brief history of meteorological $\bullet$ bservations in Finland, dating back to the seventeenth century. The charts include, in addition to isotherms, isobars, isohyets, wind-roses, and other data of usual character, a chart showing the average date of first snowfall; charts of the depth of snow-cover in each winter month; and a chart of the depth of snow on March 25th, 1899, after a period of excessive snowfall. There is also a chart showing the average date on which the ice breaks up in the spring while four charts relate to thunderstorms. Owing to the prevalence of west and southwest winds-i. e., moist, tude, Finland has not a rigorous climate. Cloudiness is excessive, but the rainfall comparatively light.

Several charts dealing with the flora and fauna conclude the part of the atlas devoted to physical geography. Finland is well covered with forests, but the true forest region is the northern half, which belongs to the wooded zone that characterizes the whole of northern Russia. The state forests (shown by a separate chart) are almost all in this zone. The greater part of the country lies within the great northern belt of conifers; but toward the north this is succeeded by a zone of birch, while in the extreme south Finland enters the oak region of central Europe.

In the treatment of the flora, the country is divided into 31 botanical provinces. The number of vascular species, indigenous or naturalized, is shown for each provinee, the total being about 2,182. Among these are 21 species of trees. The limits of cultivated plants of various species are shown on two charts; one devoted to the cereals; the other to potatoes, cabbage, clover, extiles, etc.

In the indigenous fauna of Finland there are recognized 61 species of fishes, 5 batrachians, 6 reptiles, 232 birds, and 54 mammals. The limits of certain specie are shown by charts. It is noted that a part of the faun is threatened with extinction by the advance of human settlement. This is especially brought out by chart showing the limits within which bears were shot during successive periods of years, and the relative number of lynxes shot in recent and in former times.

Ocher charts and their accompanying text give detailed information regarding fishes and fisheries, of both the seas and the inland waters. The Baltic, on account of its low salinity, is not rich in true marine fishes. Salt water and fresh water species are curiously mingled. The most abundant and economically important marine species is the Baltic herring (Clupea). The first volume of text concludes with a notice of the marine plankton, by_Prof. Levander.

\section{IL HUMAN GEOGRAPHY.}

The studies of human geography embodied in the atlas are fully as important as those relating to physical geography, and are the

\section{Trustworthy derial.} which period statistics of population began to be collected on a uniform plan by the clergy, under the auspices of the Academy of Sciences. The atlas includes graphs showing the progress of such data down to 1907 , as well as numerous charts presenting conditions at the present time, er for other specified periods. The growth of population during 157 years has been fairly uniform, except that certain definite calamities - wars, epidemics, and faminestain denite calamities - wars, epidemics, and famines have left their traces conspicuously in the curves. During the period in question the population increased from
534,065 to $3,012,849$. The chart showing the present 534,065 to $3,012,849$. The chart showing the present
density of population in each parish brings out the striking contrast between the well-populated coast regions and the very sparsely inhabited regions of the north. An even more striking chart (No. 26) shows how the population tends to cluster along the water-courses, around the lakes, and on the islands of the Abo Archipelago.

One of the most instructive charts, with its accompanying text, presents statistics of emigration (most of which is to the United States). The mean annual number of emigrants per 10,000 inhabitants, during the period 18931907 , is shown for each parish in the southern half of the country, and is seen to have been far greatest from the Österbotten coast region; especially from the governments of Uleaborg and Vasa. The total annual emigration during the above period has varied from 10,000 to 20,000. Unhappily for the country, three quarters of the emigrants are drawn from the agricultural population. Prior to 1880 , emigration was very small.

As to the races in Finland, the Finns constitute 87 per cent of the population, and the Swedes barely 13 per cent. The latter are found chiefly in Aland and the adjacent archipelago, and in certain other littoral regions. In 1900 , the language spoken by $2,352,990$ persons was Finnish; while 349,733 spoke Swedish, 5,939 Russian, and 1,925 German. Far in the north is a small population of Lapps (1,515 in 1910). Gypsies are estimated to number 1,551. It is interesting to note the encroach ments of the Finnish population upon regions formerly occupied by Swedes, as shown by the survival of Swedish place-names far in the interior, where the inhabitants are now all Finns.

The sanitary condition of the people is shown in considerable detail, with charts representing the distribution of specified diseases and defects. Pulmonary consumption causes great ravages in Finland, more especially along the western coast.
The economic life of the country is shown in a long Thes of striking and instructive charts, to which correspond the greater part of the memoirs in the second volume of text. These are so various that it is difficult to summarize them in a brief review. Two series of charts under this head deal with agriculture and manufactures, respectively. A number of ingeniously constructed graphs present a wealth of information concerning the foreign commerce of the country, and its fluctuations. Cereals and woven fabrics are the commonest objects of importation, while by far the most important exports are the products of the forests. The export trade in butter ranks pecond. Chart No. 40 shows the measures that have been taken to facilitate navigation in the difficult waters of the Gulfs of Bothnia and Finland, with their innumerable islands and intricate channels. This chart indicates the locations, kinds, and ranges of all the lighthouses on these shores, whether Finnish, Swedish, or Russian, as well as the lights on the large lakes; also the extent of the hydrographic surveys that have been carried out by the Finnish and the Russian authorities.

The inland communications of the country, by land and water, are shown in great detail. Finland is not only well supplied with roads (and in the south with railways), but it also possesses a system of water communications without rival in Europe. It has 4,060 miles of telegraph lines, and 58,400 of telephone.

The economic portion of the atlas concludes with charts relating to savings banks, the co-operative movement, and insurance. Then come charts dealing with political reography and one showing the distribution of schools and the school attendance. From these modern themes the atlas suddenly reverts to prehistoric times, with some admirable charts devoted to archæology. It is interesting to note that the remains of the stone age indicate a distribution of population in that period corresponding rather closely to that of to-day.

Last of all come charts, on a scale of 1 to 30,000 , of the 38 principal towns of Finland. These range in population from Ilelsingfors, with 137,346 inhabitants, to Nadendal, with 903 . In the text volume, the history of these towns is given in detail.

Though only a hasty sketch, the foregoing review will perhaps suffice to give an idea of the extent and variety of the material embraced in the Atlas of Finland and the two volumes of text that accompany it. The Society of Geography of Finland has furnished a striking example of what should be understood as comprising the geographical study of a country. From environing physical conditions spring, necessarily, the development and characteristics of a people; there is no physical geography without a human geograrhy, nor can one be studied without the other. They are marely two points of view, so interrelated as to be inseparable.

The geographical work undertaken by the Finnish society in accordance with this idea has been so perfectly carried out, and represents such an amount of erudition and patient research, that it may well be held up as a model for all works of the same character that may bo undertaken in other countries.

\section{Substitutes for Automobile Gasoline*} By Gail Mersereau

IUкіN the last few years the development of the automobile and the greatly increased use of gasoline in chemical extraction work, combined with the partial exhaustion of the crude petroleums rich in gasoline, has wore than doubled the cost of value of this product.

During the last year or two there has been a great demand for some cheaper substitute for use in the automobile engine. The publication in the daily papers of offers of prizes for a solution of the problem has spurred on inventors to work out many ingenious possible solutions.

Denatured alcohol can be used readily. It is clean, not so dangerous as gasoline, and will give three fourth as much mileage as gasoline per gallon (and sometimes better); but it costs much more than gasoline,
and it hardly seemis probable that the price will decrease greatly in the future.

Kerosene has been used and is being used more and more in heavy trucking. In order to use it in the ordinary motor it is simply necessary to heat the carbureter by means of the exhaust gases. The motor must be started with gasoline or alcohol. There is no (lifficulty in this, as it is easy to attach a small sup1)lementary tank.

The great drawback to the use of kerosene is its production of polymerized products in the cylinder and the formation of coke and lampblack from these products. I'his polymerization reaction takes place apparently only in the larger globules of the kerosene which enter the cylinder. The outside layer of oil is partially oxidized, with the formation of high boiling polymers. These then condense on the relatively cool

* Journal of the Society of Chemical Industry. sicles of the cylinder. Further explosions in the cylincier oxidize and burn off more of the hydrogen atom until the material becomes nearly pure carbon.

Alcohol, injected into the cylinders, while still hot, at the end of the day's work, will clean out the greater proportion of these troublesome products. This is too much trouble for the ordinary automobile owner.

To obviate the difficulties above mentioned, namely, the preheating of the carbureter and the production of coke and lampblack, a great many mixtures have been proposed.

All kinds of low boiling point constituents have been added, so that the carbureter need not be preheated, and all kinds of oxygen containing materials have been added to prevent the dehydrogenation and polymerization of the molecule.

Many mixtures of kerosene with acetone, other ketones, alcohol, casing-head gasoline, methyl, and ethyl ether, etc., have been proposed and tried. Many of these mixtures work very well, but the average owner wants a fuel that can be purchased at any point on his travels.

The Southey carbureter" or rather "gasifier" seems to work very satisfactorily. In this apparatus the kerosene is sprayed into a chamber, where the spray comes into contact with a small amount of air. A partial combustion takes places, just enough air being admitted to cause sufficient combustion to furnish the heat necessary to gasify the oil. This combustion is started by a spark, but after a minute or two the spark may be cut off. The chamber is so arranged that the large globules of oil from the spray drop to the bottom and are returned to the main tank.

The apparatus works very well in practice. It gives practically no trouble from coking or the formation of

${ }^{1}$ Southey, Eng. Pat. 27,612, December 8th, 1911.

evil-smelling products of partial combustion. Kerosene of very much the same composition can be bought all over the world. This seems to solve the problem.

Many methods ${ }^{2}$ for the manufacture of gasoline from heavy oils have been proposed and quite a number patented. The principle on which most of these work is the distillation of the heavy oil under pressure. The first lot of these gasolines to reach the New York market a year or so ago, were straw-colored, ill-smelling ils. They had been distilled carelessly and contained considerable proportions of very heavy oils, but during the last few months the quality has been much improved. These gasolines made by high pressure distillation are now being manufactured on a very large scale in this country, but the price is maintained very close to that of the natural petroleum product.

\section{Peppermint Oil in the Ukraine}

THE Ukraine is an almost unknown part of the worle, but nevertheless a vast, very fertile, and beautiful country; it consists of that portion of Southern Russi known as "Little Russia," together with Ruthenia, which embraces the Austrian provinces of Galicia and Bukovina. A sample of the peppermint oil grown in this locality has been examined and found to have the following characters: Specific gravity, 0.904; optical rotation, -26 degrees; total menthol, 53.8 per cent; esters as menthyl acetate, 6 per cent. It is soluble 1 in 3 volumes of 70 per cent alcohol, becoming slightly opalescent with 10 volumes. The rich black soil of the region and the beautiful climate are most favorable to the cultivation of essential oil-heal ling plants. A tobacco grown there, "suitably flavored with peppermint," is 